
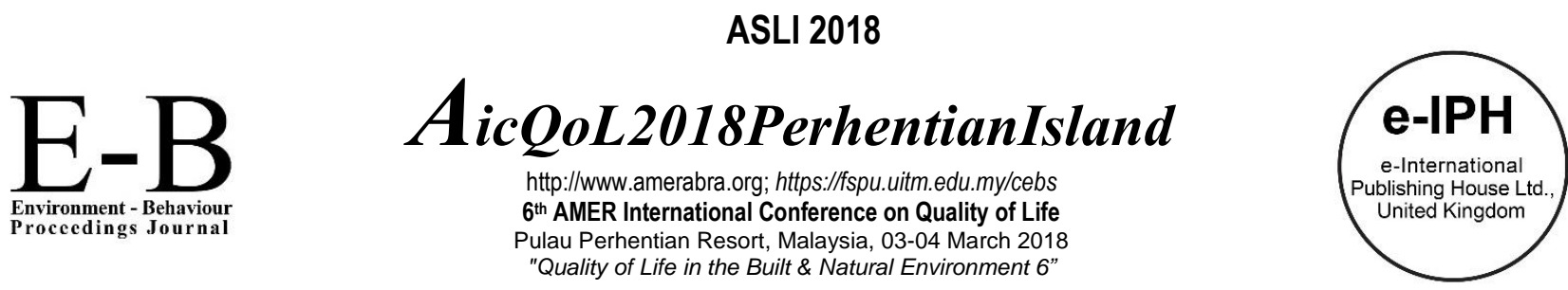

\title{
Cognitive Impairment among Young Motorcyclists: A controlled study
}

\author{
Anila Ali1,3, Roslinah Mohamad Hussain² \\ 'Department of Environmental Health and Safety, Faculty of Health Sciences, Universiti Teknologi MARA, Selangor Malaysia \\ 2Department of Medical Imaging Technology, Faculty of Health Sciences, Universiti Teknologi MARA, Selangor Malaysia \\ 3Department of Environmental Management and Policy, Faculty of Engineering, Balochistan University of Information Technology, Engineering and Management \\ Sciences, Quetta, Pakistan \\ anila928@yahoo.com \\ Tel: +60-11-25268324
}

\begin{abstract}
Cognitive assessment of young motorcyclists under high-noise exposure has not been investigated previously. Therefore, this study aimed to determine the effects of noise on cognitive function and reaction time among undergraduate motorcyclists (aged: 19-25). The study design consisted of experimental (ExG; $n=30$ ) and controlled group (CoG; $n=30)$. The ExG performed neuropsychological battery test under motorcycle noise $(85-90 \mathrm{dBA})$ and CoG under controlled laboratory noise $(\leq 65 \mathrm{dBA})$. The result revealed that the CoG had significantly better cognitive performance $(p<0.05)$ and reaction-time as compared to ExG. The results demonstrated that motorcycle noise significantly decreased cognitive performance and increased reaction time $(p<0.05)$.
\end{abstract}

Keywords: Motorcycle noise; Motorcyclists; Neuropsychological assessment; Reaction-time

eISSN: 2398-4287@ 2018. The Authors. Published for AMER ABRA cE-Bs by e-International Publishing House, Ltd., UK. This is an open access article under the CC BYNC-ND license (http://creativecommons.org/licenses/by-nc-nd/4.0/). Peer-review under responsibility of AMER (Association of Malaysian Environment-Behaviour Researchers), ABRA (Association of Behavioural Researchers on Asians) and cE-Bs (Centre for Environment-Behaviour Studies), Faculty of Architecture, Planning \& Surveying, Universiti Teknologi MARA, Malaysia.

DOI: https://doi.org/10.21834/e-bpj.v3i7.1268

\subsection{Introduction}

Motorcycle drivers are exposed to high noise levels ( $>90 \mathrm{dBA}$ ) (A Ali, Hussain, Abdullah, \& Dom, 2018). Besides being exposed to the engine noise, they also experience turbulent airflow (wind noise) around the helmet ranging from 90 to $103 \mathrm{dBA}$ (Jordan, Hetherington, Woodside, \& Harvey, 2004) as function of driving speed. Such high-intensity noise can lead to auditory (hearing deficits), and nonauditory health effects consisting of varying physiological and psychological detrimental impacts (Basner et al., 2013; Liebl \& Jahncke, 2017).

Motorcycling requires alertness, attentiveness and mental performance to carry out the task at the right moment. There is a need to accurately assess the cognitive parameters associated with driving safety (León-Domíngueza, Barrio-Álvarezc, Martínd, \& LeónCarrióne, 2016). Mental performance is a composite of alertness, learning, task management and reaction-time (Alimohammadi, Soltani, Sandrock, Azkhosh, \& Gohari, 2013). It has been reported that high-noise exposures impair mental performance (Jahncke, Hygge, Halin, Marie, \& Dimberg, 2011; Trimmel, Atzlsdorfer, Tupy, \& Trimmel, 2012). However some studies indicated that noise has no effect, and in some cases, it improves the mental performance (Mehri, Alimohammadi, Ebrahimi, Hajizadeh, \& Roudbari, 2018). In general, it has been reported that high noise exposures impair cognitive functioning because it increases the overall workload associated with a particular stimulus and it does potentially affect the visual performance (Parsons, 2000). Also, auditory distraction impairs working memory and comprehension of written materials (Trimmel et al., 2012). In contrast, it was indicated by (Helton, Matthews, \& Warm, 2009) that vigilant performance tends to be better under noise conditions and it also increases self-reported task-engagement. A recent study reported that young motorcyclist's (19-25 years) demonstrated increased physiological stress reaction due to motorcycling (Anila Ali, Dom, Hussain, \& Abdullah, 2017) and weak audiometry profile (Anila Ali, Dom, Hussain, Karuppannan, \& Abdullah, 2018).

eISSN: 2398-4287@ 2018. The Authors. Published for AMER ABRA cE-Bs by e-International Publishing House, Ltd., UK. This is an open access article under the CC BYNC-ND license (http://creativecommons.org/licenses/by-nc-nd/4.0/). Peer-review under responsibility of AMER (Association of Malaysian Environment-Behaviour Researchers), ABRA (Association of Behavioural Researchers on Asians) and cE-Bs (Centre for Environment-Behaviour Studies), Faculty of Architecture, Planning \& Surveying, Universiti Teknologi MARA, Malaysia.

DOI: https://doi.org/10.21834/e-bpj.v3i7.1268 
Previously, studies relating to physiological and psychological profile of young motorcyclists are scarce, while no studies have quantified any relation between motorcycling noise and cognitive function. Therefore, the effects of high-intensity motorcycle noise on driver's cognitive assessments remain to be studied.

One of the most widely used instruments for assessing the cognitive functioning is the Loewenstein Occupational Therapy Cognitive Assessment (LOTCA) (Katz, Elazar, \& Itzkovich, 1995). It provides a profile of the respondent's cognitive status to establish a baseline for monitoring and planning (Alghadir, Gabr, \& Al-eisa, 2016). This instrument assesses the underlying cognitive skills required for everyday functioning such as orientation, visual perception, psychomotor abilities, problem-solving skills and thinking operation. It has been used as a tool for assessing the cognitive functioning of healthy individuals (Alghadir et al., 2016) addicts (Rojo-mota et al., 2017), etc. Some research projects have proved the satisfactory psychometric properties across a diversified population and geographic areas (Rojo-mota et al., 2017).

The purpose of this study was to understand the impact of high noise exposure on the cognitive functioning of young motorcyclists. Motorcycle rider's psychological health profiling is scarce while cognitive assessment of young motorcyclists under motorcycle exposure has not been investigated previously. Therefore, this study is aimed to determine the effects of noise-induced cognitive functioning and its associated reaction-time among young motorcyclists. Also, to analysis the known-group validity of LOTCA when administered with and without noise exposure.

\subsection{Methodology}

\subsection{Study participants}

This experimental study was conducted at Universiti Teknologi MARA Selangor, Puncak Alam campus, Malaysia. Participants were undergraduate students, aged between 19 - 25 years, who had been riding the motorcycle as their primary means of transportation for a minimum of one year. A simple random technique was adopted for sampling across the different faculties, that were represented from all over Malaysia (Masuri, Dahlan, Danis, \& Isa, 2017). Inclusion criteria set for samples was (i) aged between 19 to 25 years old (Norfazila, Mustaffa, \& Ghazali, 2017); (ii) nonsmoker; (iii) absence of any chronic diseases and CGPA (Cumulative Grade Point Average) above 2.5. A set of structured questionnaires which consisted of study information sheet and respondent's demographic survey were distributed among 301 motorcyclists, while total participants recruited in the experimental phase were 60 (43 male and 17 female) based on inclusion and exclusion criteria. All participants endorsed written consent form of participation before the commencement of the experiment. Experimental procedure and design was approved by Faculty's (Health Sciences) Internal Ethical Committee (600-FSK (PT.5/2)), Universiti Teknologi Mara, Malaysia.

\subsection{Instruments}

\subsubsection{Demographic Information}

Participants demographic data were obtained through a self-reported questionnaire. The information consisted of data related to age, gender, years of motorcycling experience (as a primary mode of transportation), faculty, the semester of enrollment, CGPA of proceeding semester, motorcycle license, usage of the helmet, smoking habit and presence of any chronic diseases (diabetes mellites, hypertension, asthma).

\subsubsection{Sound Level Meter (SLM)}

Laboratory sound level during test administration was measured using the SoundPro SE and DL sound level meter (SLM) of class/type 1 (serial no BEI040002) from Quest Technologies Oconomowoc, WI, USA. Type 1 sound level was used to measure the ambient noise as the experimental group was exposed to artificially induced noise of the motorcycle. Sound levels were measured before and during the test administration.

\subsubsection{LOTCA}

LOTCA (Lowenstein Occupational Therapy Cognitive Assessment) neuropsychological battery test, Second Edition (Katz et al., 1995) was used for assessing cognitive performance of the motorcycle riders. LOTCA mainly consists of six domains, which are further divided into 26 subtests, and scored on a four- or five-point Likert scale. Domains categorization and scoring range are defined as Orientation subtest consist of two items, i.e., orientation for place and time, scores ranged from 2 to 16 on eight-point Likert scale. Visual perception subtest includes four items, i.e., visual perception for object and shape identification, figure and ground perception, and object constancy. Subset total scores can range from 4 to 16. Spatial perception subtest consists of three items: directions on respondent's body, spatial relations, and spatial relations on pictures. Subset total score can range from 3 to 12. Motor proxis subtest consists of three items, i.e., motor imitations, utilization of objects, and symbolic actions. Subset total scores can range from 3 to 12. Visual organization subtest examines perceptual-motor integration with spatial components which includes seven items, i.e., copying geometric forms, reproduction of two- and three-dimensional models, pegboard construction, coloured and plain block design, reproduction of a puzzle, and drawing of a clock. Subset total score can range from 7 to 28 . Thinking operation subtest consists of seven items. The five-point Likert scale used for three elements: categorization, Riska Object Classification (ROC) unstructured and structured. Sequencing items based on four-point Likert scales consisting of four items: pictorial classification, pictorial sequencing, and geometrical sequencing and logical questions. Subset total score ranged from 7 to 35 . Attention and concentration based on overall performance on the LOTCA. Scores range from 1 to 4 . Previous studies investigated the interrater reliability coefficients which ranged between $0.82-0.97$ for all six domains (Katz et al., 1995). 


\subsubsection{LOTCA administration procedure}

LOTCA was administered according to test manual provided in the LOTCA kit. The test was started with the Orientation domain and subsequently followed through to the sixth domain. During the test performance, observations were noted by the examiner regarding participant's attention and concentration. The confounding factors like fatigue, tiredness, and restlessness were also taken into considerations. Before scoring each subset, the examiner confirmed with the participant if the task is completed and followed to the next subtest. Duration of the test varied from person to person, but the standard time of completion was from 40 to 45 minutes. LOTCA scoring was based as per instructions from the test manual. Total score is a summation of the scores from all subtests with maximum score of 123 , and minimum score of 27 . A composite score for each domain was calculated by summing the scores of the relevant subtests where higher scores indicate better performance and vice versa. Time each participant took to complete the LOTCA was recorded as a proxy of the participant's information-processing speed.

For laboratory-controlled noise exposure studies, two tables were setup. The right-hand side of examiner's, LOTCA domains subsets organized according to administration sequence on the table while speakers and SLM were placed at the front alongwith the scoring sheet. Speakers were placed on the right and the left side of the participants. Speakers (Long lorn model SP -MN 019/U, with output RMS $3 \mathrm{~W} \times 2$, Signal-to-noise $(\mathrm{S} / \mathrm{N})$ ratio $80 \mathrm{dBA}$ ) attached to a personal computer for an audio clip of motorcycle noise. Examiner and the examinee were at face to face setting position.

\subsection{Experimental Procedure}

The experimental study design structured for assessing the cognitive functioning of the undergraduate motorcyclists under controlled laboratory setting. Two groups of respondents were formed: Control Group (CoG) and Experimental Group (ExG) with 30 participants in each group as presented in the flowchart in Figure 1. Upon arrival participants of both the groups were seated in a relaxing environment for 10 minutes and later performed the neuropsychological battery test. CoG LOTCA assessment was conducted during controlled noise exposure $(\leq 65 \mathrm{dBA})$ and ExG during high motorcycle noise exposure (85-90 dBA). Testing procedures for both the groups based on the classification of variables as presented in Table 1.

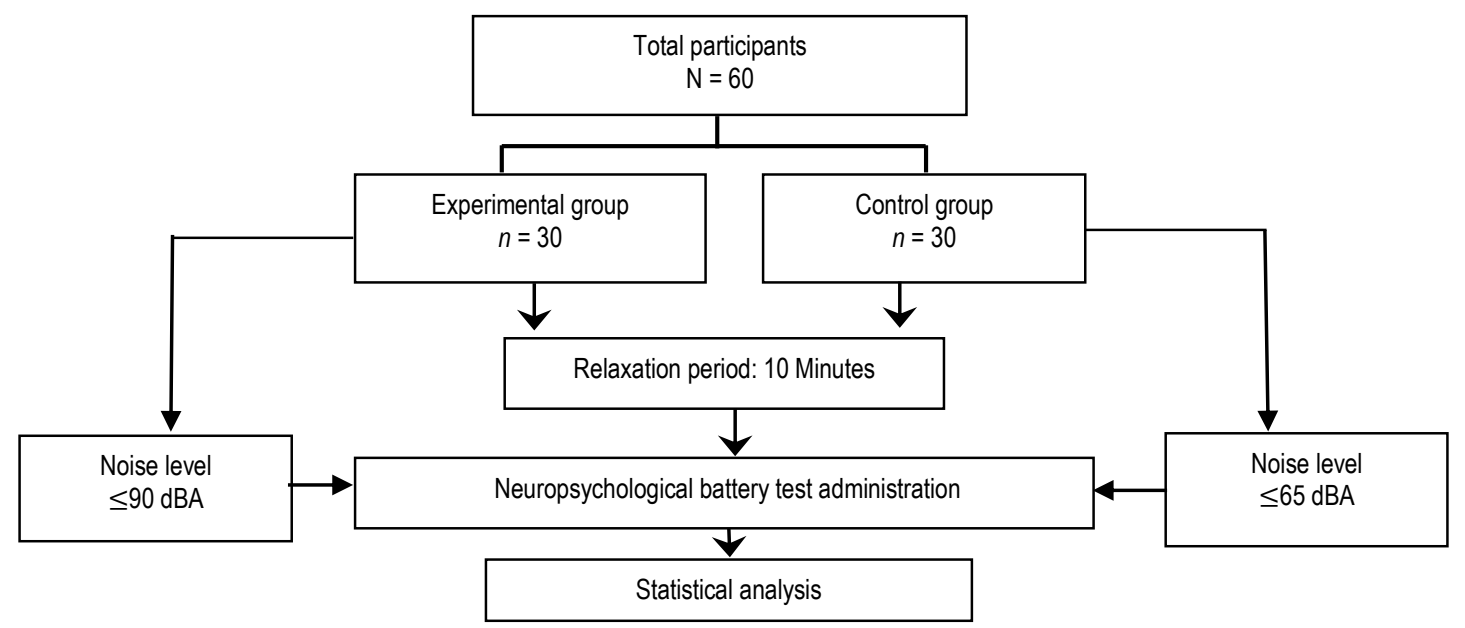

Figure 1: Experimental flow chart of the neuropsychological assessment of young motorcyclists

Table 1: Classification of variables

\begin{tabular}{|c|c|c|c|}
\hline & Independent Variables a & Controlled Variables ${ }^{\mathrm{b}}$ & Dependent Variables ${ }^{\circ}$ \\
\hline Study groups & Noise exposure & Neurological tests & Performance \\
\hline Experimental Group & YES & YES & Score's on test \\
\hline Controlled Group & NO & YES & Score's on test \\
\hline
\end{tabular}

Note: a artificially induced background motorcycle noise up to 85 to $90 \mathrm{dBA} ;{ }^{b}$ neuropsychological battery tests $\left(\right.$ LOTCA; $^{c}$ performance on the neuropsychological battery tests (LOTCA), higher the score better the performance

\subsection{Statistical Analysis}

Participants information data and LOTCA test scoring data were tabulated and logged on excel worksheet for database and computed for statistical analysis through Statistical Package for Social Sciences, IBM SPSS (Version 22 Inc., Chicago, IL). Descriptive data of variables, i.e., age, gender, semester enrollment was obtained through frequency table while the relationship between variables computed through cross-tabulation. Statistical significance was obtained by Independent sample t-test to determine the difference between experimental and control group's LOTCA performance on all domains and to evaluate the difference in reaction time (seconds) 
among groups performance on different domains. Bar charts were plotted to demonstrate the differences in the performance among groups across all LOTCA domains and reaction time. An alpha level of 0.05 used for subsequent all analysis.

\subsection{Results}

\subsection{Descriptive profile of the participants}

Table 2 presents the demographic profile of the participants $(n=60)$ recruited in the laboratory experiment for exploring the effects of noise-induced cognitive function and reaction time (seconds). Participation was dominated by male riders with $71.7 \%(n=43)$ than female riders $(n=17,28.3 \%)$. Participants mean age was $22.02(S D=1.17)$ which ranged from 19 to 25 years. The undergraduate motorcyclists ranged from semester 1 till 8 , with the mean of $4.65(S D=1.54)$ while the driving experience ranged from 1 to 12 years $(M=6.78 ; S D=2.55)$. The CGPA of the participants ranged between 2.7 to $4(M=3.22 ; S D=0.26)$.

The Control group consisted of $80 \%$ males $(n=24)$ and $20 \%$ females $(n=6)$. Participants mean age was $21.87(S D=1.41)$ which ranged from 20 to 25 years. Participation of respondents represented from semester 1 to 7 , with a mean semester of $4.57(S D=1.56)$ while driving experience ranged from 1 to 12 years $(M=6.67 ; S D=2.88)$. The average CGPA of the participants was $3.17(S D=0.26)$, ranged from 2.7 to 3.6. Experimental group constituted of $63.3 \%$ of males $(n=19)$ and $36.7 \%$ of female riders $(n=11)$. Participants mean age was $22.2(S D=0.87$ ) which ranged between 19 to 24 years. Participation of motorcyclists enrolled from semester 2 till 8 ( $M$ $=4.7 ; S D=1.55)$ while driving age ranged between 2 to 11 years of experience, with a mean driving age of $6.9(S D=2.25)$. The average CGPA of the motorcyclist's students was $3.26(S D=0.26)$, ranged between 2.7 to 4 .

Table 2: Demographic profile of motorcyclists who participated in the field experiment

\begin{tabular}{|c|c|c|c|}
\hline Variables & $\begin{array}{l}\text { Total } \\
N=60\end{array}$ & $\begin{array}{c}\text { Control Group } \\
n=30\end{array}$ & $\begin{array}{l}\text { Experimental group } \\
\qquad n=30\end{array}$ \\
\hline Gender (M/F) & $\begin{array}{c}43 / 17 \\
M \pm S D, \text { range }\end{array}$ & $\begin{array}{c}24 / 6 \\
M \pm S D, \text { range }\end{array}$ & $\begin{array}{c}19 / 11 \\
M \pm S D, \text { range }\end{array}$ \\
\hline Age, (yrs.) & $22.02 \pm 1.17,19-25$ & $21.87 \pm 1.41,20-25$ & $22.2 \pm 0.87,19-24$ \\
\hline $\begin{array}{l}\text { Semester } \\
\text { Driving age } \\
\text { CGPA }\end{array}$ & $\begin{array}{c}4.65 \pm 1.54,1-8 \\
6.78 \pm 2.55,1-12 \\
3.22 \pm 0.26,2.7-4 \\
\end{array}$ & $\begin{array}{l}4.56 \pm 1.56,1-7 \\
6.67 \pm 2.88,1-12 \\
3.17 \pm 0.26,2.7-3.6\end{array}$ & $\begin{array}{l}4.7 \pm 1.55,2-8 \\
6.9 \pm 2.25,2-11 \\
3.26 \pm 0.26,2.7-4\end{array}$ \\
\hline
\end{tabular}

\subsection{Descriptive analysis of LOTCA assessment}

Table 3 presents the detailed descriptive and statistical analysis of the ExG and CoG LOTCA assessment across all domains and reaction-time (seconds). The first domain of LOTCA i.e., Orientation was found significantly higher in CoG $(M=15.80, S D=0.55)$ as compared to $\operatorname{ExG}(M=15.35, S D=0.92), t(47.36)=-2.379, p=0.021$. Figure $2 A$ shows the difference in Orientation performance between ExG and CoG which reflects the effect of noise on ExG lower performance as compared to CoG better performance.

Table 3: Descriptive and statistical analysis of the LOTCA assessment

\begin{tabular}{|c|c|c|c|c|c|c|c|}
\hline LOTCA Domains & Groups & Possible range & Mean \pm SD & Range & Minimum & Maximum & P-value \\
\hline \multirow[t]{3}{*}{ Orientation } & & $2-16$ & & & & & \\
\hline & Experimental group & & $15.35 \pm 0.92$ & 4 & 12 & 16 & 0.021 \\
\hline & Control group & & $15.80 \pm 0.55$ & 2 & 14 & 16 & \\
\hline \multirow[t]{3}{*}{ Visual Perception } & & $4-16$ & & & & & \\
\hline & Experimental group & & $15.13 \pm 0.82$ & 2 & 14 & 16 & 0.010 \\
\hline & Control group & & $15.63 \pm 0.61$ & 2 & 14 & 16 & \\
\hline \multirow[t]{3}{*}{ Spatial Perception } & & $3-12$ & & & & & \\
\hline & Experimental group & & $11.86 \pm 0.82$ & 1 & 11 & 12 & 0.043 \\
\hline & Control group & & $12.0 \pm 0$ & 0 & 12 & 12 & \\
\hline \multirow[t]{3}{*}{ Motor Praxis (Score) } & & $3-12$ & & & & & \\
\hline & Experimental group & & $11.09 \pm 0.91$ & 3 & 9 & 12 & 0.000 \\
\hline & Control group & & $11.93 \pm 0.25$ & 1 & 11 & 12 & \\
\hline \multirow[t]{2}{*}{ Visual Organization (Score) } & & $7-28$ & & & & & \\
\hline & Experimental group & & $24.42 \pm 1.8$ & 7 & 21 & 28 & 0.000 \\
\hline
\end{tabular}




\begin{tabular}{|c|c|c|c|c|c|c|c|}
\hline & Control group & & $27.1 \pm 0.80$ & 2 & 26 & 28 & \\
\hline & Experimental group & & $443.7 \pm 157.81$ & 750 & 270 & 1020 & 0.002 \\
\hline & Control group & & $311 \pm 151.7$ & 620 & 160 & 780 & \\
\hline \multirow[t]{3}{*}{ Thinking Operation (Score) } & & $7-35$ & & & & & \\
\hline & Experimental group & & $27.09 \pm 2.30$ & 10 & 21 & 31 & 0.000 \\
\hline & Control group & & $29.4 \pm 1.6$ & 7 & 24 & 31 & \\
\hline \multicolumn{8}{|l|}{$\begin{array}{l}\text { Thinking Operation } \\
\text { (Time-seconds) }\end{array}$} \\
\hline & Experimental group & & $655.7 \pm 239.9$ & 940 & 320 & 1260 & 0.000 \\
\hline & Control group & & $444 \pm 197.4$ & 760 & 260 & 1020 & \\
\hline \multirow[t]{3}{*}{ Attention and Concentration } & & $1-4$ & & & & & \\
\hline & Experimental group & & $3.47 \pm 0.51$ & 1 & 3 & 4 & 0.000 \\
\hline & Control group & & $3.9 \pm 0.31$ & 1 & 3 & 4 & \\
\hline \multirow[t]{3}{*}{ LOTCA (Score) } & & $27-123$ & & & & & \\
\hline & Experimental group & & $104.9 \pm 4.3$ & 17 & 93 & 110 & 0.000 \\
\hline & Control group & & $111.9 \pm 2.8$ & 11 & 100 & 111 & \\
\hline \multicolumn{8}{|l|}{ LOTCA (Time- seconds) } \\
\hline & Experimental group & & $3176 \pm 353.4$ & 1500 & 2400 & 3900 & 0.000 \\
\hline & Control group & & $2193 \pm 419.7$ & 1380 & 1500 & 2880 & \\
\hline
\end{tabular}

Visual Perception, the second domain of LOTCA was found significantly higher in CoG $(M=15.63, S D=0.61)$ as compared to ExG $(M=15.13, S D=0.82), t(58)=-2.673, p=0.010$. Figure 2B shows the difference in Visual Perception domain of LOTCA among ExG and $\mathrm{CoG}$, presenting a significantly better performance of the $\mathrm{CoG}$ as compared to ExG. The results revealed that the influence of noise on Visual Perception tends to decrease as compared to under low-noise levels.

The third domain of LOTCA i.e., Spatial Perception was also found significantly higher in CoG $(M=12, S D=0)$ as compared to ExG $(M=11.86, S D=0.82), t(29)=-2.112, p=0.043$. Figure $2 C$ presents the Spatial Perception assessment difference among ExG and $\mathrm{CoG}$, indicating higher performance by the COG. The results showed the decreased Spatial Perception among the participants performed under high-noise exposures (ExG). The results suggested that noise effects the Spatial Perception by decreasing its efficiency.

The LOTCA's fourth domain was related to Motor Praxis which was also found significantly higher in CoG $(M=11.93, S D=0.25)$ as compared to ExG $(M=11.09, S D=0.91), t(33.51)=-5.039, p=0.000$. Figure $2 \mathrm{D}$ reflects the higher performance by the CoG then ExG in Motor Praxis. The results indicate the negative influence of noise on participants (ExG) Motor Praxis ability, while under low noise exposure the performance tends to be better (CoG).

The fifth domain of LOTCA i.e., Visuomotor Organization domain based on its average score was found significantly higher in CoG $(M=27.1, S D=0.80)$ as compared to ExG $(M=24.42, S D=1.83), t(39.733)=-7.207, p=0.000$. The reaction-time associated with the completion of Visuomotor Organization domain (seconds) was found significantly higher in ExG $(M=443.67, S D=157.82$ ) as compared to CoG $(M=311, S D=151.7), t(58)=3.319, p=0.002$. Figure $2 \mathrm{E}$ shows the better performance by the CoG then ExG based on its average score. Figure $2 \mathrm{~F}$ shows the difference in the reaction-time between the two groups indicating the higher reactiontime by ExG. The results revealed that CoG conducted a better performance with speeded reaction-time in the completion of Visuomotor Organization.

Thinking Operation, the sixth domain of the LOTCA assessed on its average score which was found significantly higher in CoG ( $M$ $=29.4, S D=1.63)$ as compared to ExG $(M=27.09 S D=2.30), t(58)=-4.591, p=0.000$. The reaction-time associated with its completion was found significantly higher in ExG $(M=655.67, S D=239.9)$ as compared to $\operatorname{CoG}(M=444, S D=197.4), t(58)=3.731$, $p=0.000$. The overall results for average score and reaction-time associated with the performance of Thinking Operation domain indicate that the noise impacts the negative effects and hinders the efficiency of the thinking. Figure $2 \mathrm{G}$ shows the differences in the performance between $\mathrm{CoG}$ and $\mathrm{ExG}$ on Thinking Operation while indicating a better score of $\mathrm{CoG}$. Figure $2 \mathrm{H}$ presents the reaction-time (seconds) associated with the performance of the Thinking Operation domain between the two groups, where ExG took larger time in completion of the domain as compared to CoG. 
Thinking Operation, the sixth domain of the LOTCA assessed on its average score which was found significantly higher in CoG ( $M$ $=29.4, S D=1.63)$ as compared to $\operatorname{ExG}(M=27.09 S D=2.30), t(58)=-4.591, p=0.000$. The reaction-time associated with its completion was found significantly higher in $\operatorname{ExG}(M=655.67, S D=239.9)$ as compared to $\operatorname{CoG}(M=444, S D=197.4), t(58)=3.731$, $p=0.000$. The overall results for average score and reaction-time associated with the performance of Thinking Operation domain indicate that the noise impacts the negative effects and hinders the efficiency of the thinking. Figure $2 G$ shows the differences in the performance between $\mathrm{CoG}$ and ExG on Thinking Operation while indicating a better score of $\mathrm{CoG}$. Figure $2 \mathrm{H}$ presents the reaction-time (seconds) associated with the performance of the Thinking Operation domain between the two groups, where ExG took larger time in completion of the domain as compared to $\mathrm{CoG}$.

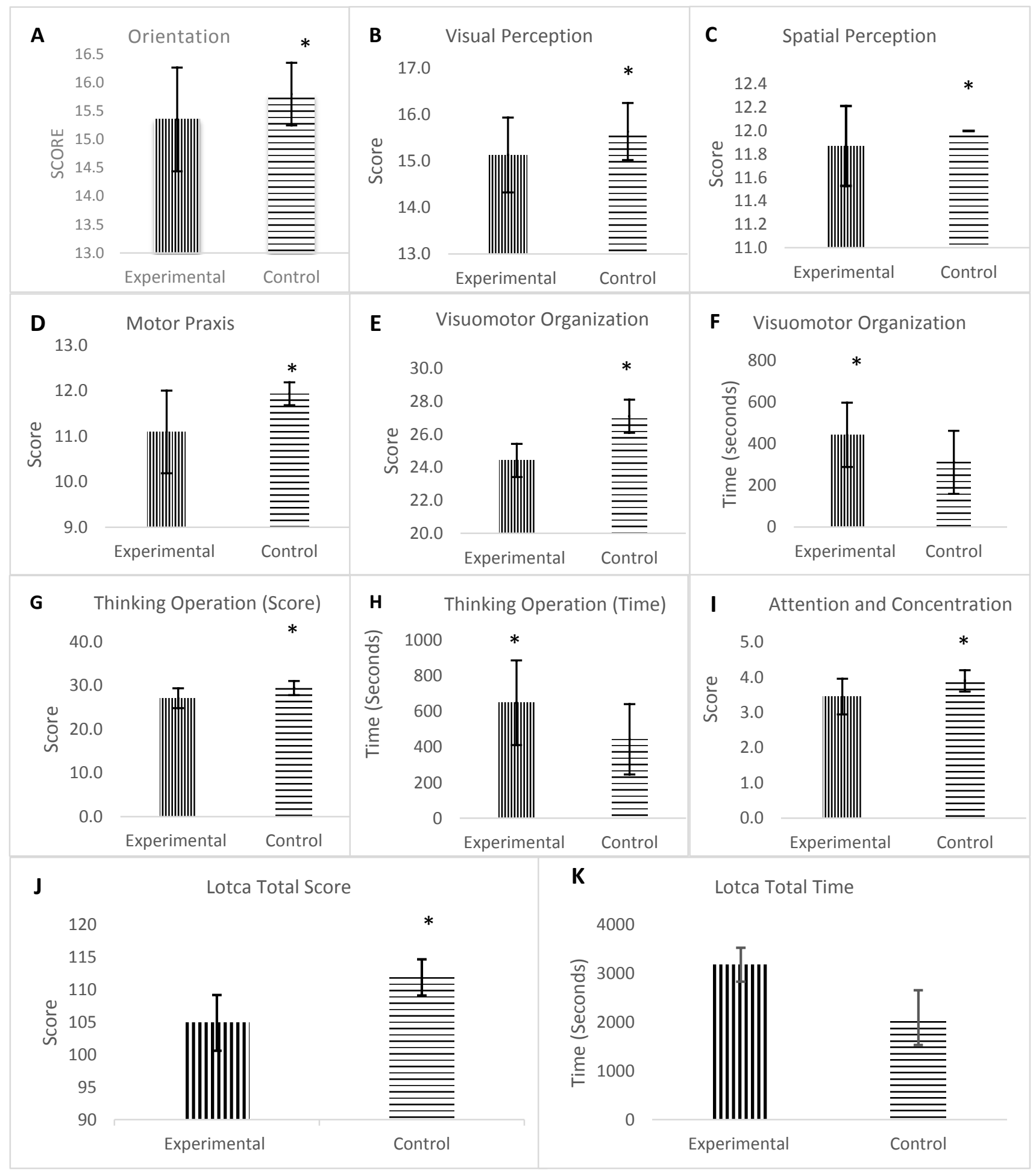


Figure 2: LOTCA domains differences between Experimental and Control group: (A) Orientation; (B Visual Perception; (C) Spatial Perception; (D) Motor Praxis; (E) Visuomotor Organization (score); (F) Visuomotor Organization (time); (G) Time Operation (score); (H) Time Operation (time); (I) Attention and Concentration: (J) LOTCA Total Score: (K) LOTCA Total Time. Note: (*) p-value $<0.05$ between experimental and control group.

The Attention and Concentration based on overall performance were also found significantly higher in $\operatorname{CoG}(M=3.9, S D=0.31)$ as compared to ExG $(M=3.47, S D=0.51), t(58)=-4.009, p=0.000$. Figure 2l presents the difference between the two groups where CoG showed better Attention and Concentration while performing the LOTCA assessment. The results indicate that the effect of noise had degraded the Attention and Concentration of participants during the assessment.

The cumulative score of LOTCA domains was found significantly higher in CoG $(M=111.9, S D=2.8)$ as compared to ExG ( $M=$ 104.9, $S D=4.3), t(48)=-7.355, p=0.000$. While the total time (seconds) consumed in completion of LOTCA assessment was found significantly higher in ExG $(M=3176, S D=353.36)$ as compared to CoG $(M=2192, S D=419.47), t(58)=9.826, p=0.000$. These results suggest that the effect of high-noise exposure had affected the performance of the participants by scoring lower with higher reaction-time. Figure $2 \mathrm{~J}$ and $2 \mathrm{~K}$ present the average score performances of LOTCA and reaction time of both the groups respectively.

Overall our results suggest that the high noise-exposure does influence cognitive functioning and its associated reaction-time. The results revealed that when motorcycle riders are exposed to high noise levels, their cognitive functioning and reaction-time response to cognitive demanding stimulus decreases.

\subsection{Discussion}

This study compared the performance of young motorcyclists on the LOTCA under motorcycle noise exposure $(\leq 90 \mathrm{dBA})$ and controlled laboratory noise $(\leq 65 \mathrm{dBA})$. LOTCA is a relatively systematic test attributed as a useful test for an initial assessment of neurobehavioral problems such as addiction, intellectual disabilities, head injuries, etc. and tends to possess the characteristics of the good instrument for cognitive screening. However, its use among the current population, i.e., young motorcyclists has never been established. Therefore, this study aimed to check the differential effect of noise on LOTCA assessment for cognitive profiling of motorcyclist with respect to performance and reaction time.

Overall, both groups (ExG and CoG) obtained scores that were close to the maximum possible (Table 2) in each domain. However, on average LOTCA score, there was a significant difference $(p<0.05)$ in the performance which can be attributed to the effect of noise. Hence, this suggest that LOTCA is a simple cognitive test, can be used to quantify the effects of noise based on performance and reaction time. Other experimental studies performed on different populations that also evaluated the effect of noise on performance showed a significant relation of noise with impairment performance (Jahncke et al., 2011)(Waye et al., 2002). The findings of this study are in contrast with the recent study reported (Mehri et al., 2018) in which a positive relation was shown between complex task and high traffic noise exposure as compared to a simple task. It can also be assumed that the results of this study may have been affected by the cognitive assessments of the individuals which usually affects the performance (Mehri et al., 2018). Cognitive assessment refers to the evaluation of the situation. In this study, the participants were presumably aware of the effects of noise on mental performance as they all were undergraduate students.

Time pressure can affect the judgment of workload by a decline in performance (Etkin \& Wager, 2007). In this study, LOTCA administration time was kept flexible and relaxed for task completion for each domain for both the groups. Significant differences $(p<$ 0.05) in speeded reaction-time for Visuomotor Organization and Thinking Operation domains were observed for CoG, while ExG performance exhibited delayed performance. Overall CoG showed better LOTCA average score and dominated by significantly better reaction-time as compared to ExG.

Regarding known-group validity, Visual Organization was the most sensitive domain with the difference of $\sim 11 \%$ in detecting the difference between noise and non-noise exposed groups. Subsequently, followed by Thinking Operation with the difference of $\sim 9 \%$ and next by Motor Praxis with the difference of $\sim 8 \%$. For the average LOTCA scores, the difference between the groups was $\sim 7 \%$. Visuomotor Organization comprises of drawing, coping building and assembling. This domain has a spatial component which involves perceptual activities with motor responses (Uyanik, Aki, Ger, Gonca Bumin, \& Kayihan, 1999). Disparities in drawing a symmetrical object reflect the unilateral neglect and a person's ability to process the spatial relations (Cooke, Mckenna, Fleming, \& Darnell, 2006). The visual attention disruption has an adverse effect on daily activity functioning, mainly that require inspection integration of visual details with the dynamic environment such as driving (Warren, M., Pendleton, H.M. and Schultz-Krohn, 2006). Building and assembling difficulties suggest constructional problem and hinder daily activities of any complicated kind (Jang, Chern, \& Lin, 2009). According to Parsons, 2000 visual performance is affected by high-intensity noise. Therefore, it can be concluded that under motorcycle noise exposure motorcyclists Visuomotor Organization can be affected and can pose a safety risk. Thinking Operation domain of LOTCA involves higher mental abilities of problem-solving, concept shifting, abstraction, executive functions, logical operation and calculations (Itzkovich, Malka, Elazar, \& Averbuch, 2000). It has also been reported that prolonged noise exposure degenerates cognitive function and increases the risk of accidents (Anila Ali et al., 2016).

A review study by Liebl \& Jahncke, 2017 on the effects of noise on cognitive performance reported that individuals with lower working capacity are more vulnerable to noise effects. Another review by Tzivian et al., 2015 stated that noise is associated with several indicators of neurocognitive function, mood disorders and neurodegenerative diseases on long-term noise-exposed population.

Emphasis should be placed by policymakers to conduct cognitive function assessment of motorcyclists before accomplishing the driver's license and should be re-administrated over time. While in the case of minor or major road accidents, motorcyclist's cognitive assessment should be enforced as a law. The limitation of this study was the incomparable population with other studies. The second limitation was that participants administration time could not have been standardized because of their class schedules. The strength of 
the study was the diversified demographic participants and larger sample size. For future studies, the individual parameters such as personality type, subjective noise measurement, socioeconomic levels, and annoyance should be included to draw the comprehensive effects of noise on cognitive functioning.

\subsection{Conclusion}

This study aimed to investigate the effect of motorcycle exposure on neuropsychological performance about reaction-time of young motorcyclists. Results revealed that motorcycle noise, as a source of stressor, had affected the performance of the cognitive performance including orientation, visual perception, motor praxis, thinking operation, visuomotor organization, attention and concentration along with decreased reaction time. Performance comparison between the participants who performed under control noise levels ( $\geq 65 \mathrm{dBA})$ and high noise exposure ( $>90 \mathrm{dBA}$ ) validates the negative influence of noise on cognitive function. There is a need for studies investigating motorcycle noise exposure assessments on mental health of young riders by using standardized methods and protocols for future cross-sectional and epidemiological references.

\section{Acknowledgement}

This study was funded by Lestari Grant, University Technology Mara, Award Number: 600-RMI/MYRA 5/3 LESTARI (0016/2016) for providing complimentary vouchers to participants for participation.

\section{References}

Alghadir, A. H., Gabr, S. A., \& Al-eisa, E. S. (2016). Effects of Moderate Aerobic Exercise on Cognitive Abilities and Redox State Biomarkers in Older Adults. OxidativeMedicine and Cellular Longevity, 1-8.

Ali, A., Dom, N. C., Hussain, R. M., \& Abdullah, M. (2017). A QoL2017Kuching Effect of Motorcycling on Salivary Noise-Induced Cortisol among Young Motorcyclists. Environment-Behaviour Proceedings Journal, 2(6), 269-277.

Ali, A., Dom, N. C., Hussain, R. M., Karuppannan, S., \& Abdullah, M. (2018). Auditory Profile of Undergraduate University Motorcyclists : Prevalence of Hearing Loss and Hearing Impairment. EnvironmentAsia, 11, 217-229. http://doi.org/10.14456/ea.2018.16

Ali, A., Hussain, R. M., Abdullah, M., \& Dom, N. C. (2018). AT-EAR NOISE LEVELS UNDER THE HELMET: A FIELD STUDY ON NOISE EXPOSURE OF YOUNG MOTORCYCLISTS. Journal of Fundamental and Applied Sciences, 10(3S), 218-231.

Ali, A., Karuppannan, S., Hussain, R. M., Rajan, S., Abdullah, M., Ikhwan, R., \& Chinna, K. (2016). Epidemiological root cause analysis of noise and physio - psycho impacts related to motorcycle road accidents. Journal of Scientific Research and Development, 3(5), 150-156. Retrieved from http://jsrad.org/wp-content/2016/lssue 5, 2016/23j.pdf

Alimohammadi, I., Soltani, R., Sandrock, S., Azkhosh, M., \& Gohari, M. R. (2013). The effects of road traffic noise on mental performance. Iranian Journal of Environmental Health Science \& Engineering, 1-5.

Basner, M., Babisch, W., Davis, A., Brink, M., Clark, C., Janssen, S., \& Stansfeld, S. (2013). Auditory and non-auditory eff ects of noise on health. Lancet, 6736(13), 18. http://doi.org/10.1016/S0140-6736(13)61613-X

Cooke, D. M., Mckenna, K., Fleming, J., \& Darnell, R. (2006). Construct and ecological validity of the Occupational Therapy Adult Perceptual Screening Test ( OT-APST ). Scandinavian Journal of Occupational Therapy, 13(January 2005), 49-61. http://doi.org/10.1080/11038120500363014

Etkin, A., \& Wager, T. D. (2007). Reviews and Overviews Functional Neuroimaging of Anxiety : A Meta-Analysis of Emotional Processing in PTSD, Social Anxiety Disorder , and Specific Phobia. Am J Psychiatry, (October), 1476-1488.

Helton, W. S., Matthews, G., \& Warm, J. S. (2009). Stress state mediation between environmental variables and performance : The case of noise and vigilance. Acta Psychologica, 130(3), 204-213. http://doi.org/10.1016/j.actpsy.2008.12.006

Itzkovich, Malka, Elazar, B., \& Averbuch, S. Loewenstein occupational therapy cognitive assessment (LOTCA) manual (2000). Maddak Incorporated.

Jahncke, H., Hygge, S., Halin, N., Marie, A., \& Dimberg, K. (2011). Open-plan of fi ce noise : Cognitive performance and restoration. Journal of Environmental Psychology, 31(4), 373-382. http://doi.org/10.1016/j.jenvp.2011.07.002

Jang, Y., Chern, J., \& Lin, K. (2009). Validity of the Loewenstein Occupational Therapy Cognitive Assessment in People With Intellectual Disabilities. American Journal of Occupational Therapy, 63(4), 414-422.

Jordan, C., Hetherington, O., Woodside, A., \& Harvey, H. (2004). Noise induced hearing loss in occupational motorcyclists. Journal of Environmental Health Research, 3(2), 70-77.

Katz, N., Elazar, B., \& Itzkovich, M. (1995). Construct validity of a geriatric version of the Loewenstein Occupational Therapy Cognitive Assessment (LOTCA) battery. Physical Occupational Therapy in Geriatrics, 13(3), 31-47.

León-Domíngueza, U. I. S.-M., Barrio-Álvarezc, E., Martínd, J. M. B. y, \& León-Carrióne, J. (2016). Applied Neuropsychology : Adult Safe Driving and Executive Functions in Healthy. APPLIED NEUROPSYCHOLOGY: ADULT, 9095(May). http://doi.org/10.1080/23279095.2015.1137296

Liebl, A., \& Jahncke, H. (2017). Review of research on the effects of noise on cognitive performance 2014-2017. In 12th ICBEN Congress on Noise as a Public Health 
Problem.

Masuri, M. G., Dahlan, A., Danis, A., \& Isa, K. A. (2017). Attitude towards Safe Driving Scale ( ASDS-46) as a Future Predictor in Determining a Young Adult Quality Of Life : Part II. Environment-Behaviour Proceedings Journal, 2(5), 363. http://doi.org/10.21834/e-bpj.v2i5.705

Mehri, A., Alimohammadi, I., Ebrahimi, H., Hajizadeh, R., \& Roudbari, M. (2018). Effect of traffic noise on mental performance with regard to introversion and task complexity. Applied Acoustics, 132(November 2017), 118-123. http://doi.org/10.1016/j.apacoust.2017.11.019

Norfazila, D., Mustaffa, A., \& Ghazali, M. (2017). Speeding Intention among Young Urban Drivers. Asian Journal of Behavioural Studies, AjBeS, 2(7), 43-51.

Parsons, K. C. (2000). Environmental ergonomics : a review of principles, methods and models. Applied Ergonomics, 31, 581-594.

Rojo-mota, G., Pedrero-pérez, E. J., León, J. M. R. De, León-frade, I., Aldea-poyo, P., Alonso-rodríguez, M., ... Morales-alonso, S. (2017). Loewenstein Occupational Therapy Cognitive Assessment to Evaluate People with Addictions. Occupational Therapy International, 2017, 1-7.

Trimmel, M., Atzlsdorfer, J., Tupy, N., \& Trimmel, K. (2012). Effects of low intensity noise from aircraft or from neighbourhood on cognitive learning and electrophysiological stress responses. International Journal of Hygiene and Environmental Health, 215(6), 547-554. http://doi.org/10.1016/j.jhheh.2011.12.007

Tzivian, L., Winkler, A., Dlugaj, M., Schikowski, T., Vossoughi, M., Fuks, K., ... Hoffmann, B. (2015). Effects of long-term outdoor air pollution and noise on cognitive and psychological functions in adults. International Journal of Hygiene and Environmental Health, 218(1), 1-11. http://doi.org/10.1016/j.jiheh.2014.08.002

UYANIK, M., AKI, E., GER, T. D., GONCA BUMIN, \& KAYIHAN, H. (1999). Cognition in $4 \pm 11$ year old children in Turkey. PEDIATRIC REHABILITATION, 3(3).

Warren, M., Pendleton, H.M. and Schultz-Krohn, W. (2006). Evaluation and treatment of visual deficits following brain injury. Occupational Therapy: Practice Skills for Physical Dysfunction, 532-572.

Waye, K. P., Bengtsson, J., Rylander, R., Hucklebridge, F., Evans, P., \& Clow, A. (2002). Low frequency noise enhances cortisol among noise sensitive subjects during work performance. Life Sciences, 70, 745-758. http://doi.org/10.1016/S0024-3205(01)01450-3 